\title{
Mid-Infrared Imaging Is Able to Characterize and Separate Cancer Cell Lines
}

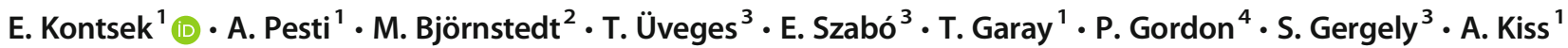

Received: 23 January 2020 / Accepted: 19 May 2020 / Published online: 16 June 2020

(C) The Author(s) 2020

\begin{abstract}
Malignancies are still responsible for a large share of lethalities. Macroscopical evaluation of the surgical resection margins is uncertain. Big data based imaging approaches have emerged in the recent decade (mass spectrometry, two-photon microscopy, infrared and Raman spectroscopy). Indocianine green labelled MS is the most common approach, however, label free midinfrared imaging is more promising for future practical application. We aimed to identify and separate different transformed (A-375, HT-29) and non-transformed (CCD986SK) cell lines by a label-free infrared spectroscopy method. Our approach applied a novel set-up for label-free mid-infrared range classification method. Transflection spectroscopy was used on aluminium coated glass slides. Both whole range spectra $\left(4000-648 \mathrm{~cm}^{-1}\right)$ and hypersensitive fingerprint regions $\left(1800-648 \mathrm{~cm}^{-1}\right)$ were tested on the imaged areas of cell lines fixed in ethanol. Non-cell spectra were possible to be excluded based on mean transmission values being above $90 \%$. Feasibility of a mean transmission based spectra filtering method with principal component analysis and linear discriminant analysis was shown to separate cell lines representing different tissue types. Fingerprint region resulted the best separation of cell lines spectra with accuracy of $99.84 \%$ at 70-75 mean transmittance range. Our approach in vitro was able to separate unique cell lines representing different tissues of origin. Proper data handling and spectra processing are key steps to achieve the adaptation of this dye-free technique for intraoperative surgery. Further studies are urgently needed to test this novel, marker-free approach.
\end{abstract}

Keywords Cancer $\cdot$ FT-IR · Fingerprint region $\cdot$ Transflectance

\section{Introduction}

Malignancies represent a huge burden on the society and the costs of novel oncological therapies are ever increasing [1]. Moreover, precise, personalized and fast multidisciplinary team decision is required to start the proper therapy [2].

E. Kontsek

kontsek.endre@med.semmelweis-univ.hu

1 2nd Department of Pathology, Semmelweis University, Budapest, Hungary

2 Laboratory for Clinical Pathology and Cytology, Department of Laboratory Medicine, Division of Pathology, Karolinska Institutet, Karolinska University Hospital, Stockholm, Sweden

3 Department of Applied Biotechnology and Food Science, Budapest University of Technology and Economics, Budapest, Hungary

4 Department of Electronics Technology, Budapest University of Technology and Economics, Budapest, Hungary
Positive surgical margin (PSM) means that the resection margin is not tumor-free. This information is delivered by the pathology report and influences the therapeutical decision [3]. In the operating rooms the routine pathology background is not available on site, however, there is an urgent intraoperative clinical need to gain information on resected tissues, especially regarding the margins. In such cases intraoperative questions are raised to be answered by the pathologist who is situated in another location or building to where fresh tissue samples must be presented for histopathology. Frozen sections are cut and stained in the pathology department, which procedure takes about 15-30 min while the surgeons are waiting for answers in order to reach clinical decision. This procedure lengthens the operation time and the frozen sections deliver less precise morphology due to the lack of proper dehydration, which increases the uncertainty of diagnoses.

There are intriguing directions concerning the development of imaging techniques that might be integrated into routine pathology. These state of the art novel technologies include mass spectrometry, vibrational microscopy, multi-photon 
microscopy and different applications of confocal technologies. Several devices and their applications aiming at intraoperative imaging and identification of tissue types have reached the developmental stage, which allows the testing of the potential of these technologies in the operating rooms. Development of novel methods has recently entered not only into the phase of experimental setups but also that of possible application as diagnostic tools. Mass spectrometry analysis of molecules gained by evaporation of tissues is a destructive analytic method [4].

Infrared spectroscopy covers a spectral range over $780 \mathrm{~nm}$. This spectrum is conventionally divided into near-, mid- and far infrared ranges (NIR 780-2500 nm, MIR 2500$25,000 \mathrm{~nm}$, FIR higher than $25,000 \mathrm{~nm}$, respectively). The lower the wavelength, the higher the energy of the light. In the past decade, tumorous specimens have been increasingly investigated by infrared spectroscopy based imaging [5-7]. The most frequently used application is still NIR, coming with more irradiated energy than MIR and thus deeper penetration in tissues [8]. Labelled and label-free approaches are used. There are known and biocompatible NIR active dye molecules available. Indocyanine green is the most frequently used in animal models [9] and its human application has been tested on liver carcinomas [10]. However, label free MIR is more promising for future practical application.

MIR spectroscopy fits more into the conventional pathological information, since the MIR photons contain less energy, consequently their spatial penetration is shorter, moreover, the signal-to-noise ratio of the MIR spectra is about two orders of magnitude higher than in case of NIR. In other words, the analysis of diagnostic MIR spectra is more reliable.

The mid-infrared area $\left(4000-650 \mathrm{~cm}^{-1}\right)$ includes the socalled fingerprint region $\left(1800-400 \mathrm{~cm}^{-1}\right)$ where peaks representative for lipids, protein, amide I/II and nucleic acids [11]. As the name suggests, fingerprint region is a specific part of the spectrum, generally containing most of the peaks.

Accordingly, the medical application of MIR is fewer than for NIR. MIR optical fibers have been commercially available since 2016, whereas previously laboratory tools existed only [12-14]. In a study, breast cancer imaging of 15 patients was carried out using mid- and long wave infrared cameras. The tumorous regions of the breast were identified using a Quantum Well Infrared Photodetector (QWIP) camera system [15]. In another study, urine samples from a small cohort of healthy women as well as female patients with gynaecological malignancies were investigated with MIR resulting in a high value of diagnostic accuracy using Principal Component Analysis (PCA) with support vector machine and genetic algorithm together with Linear Discriminant Analysis (LDA) algorithms [16]. The effect of basic tissue processing of pathological specimens (drying, formalin fixation, ethanol dehydration) on MIR spectrum was tested and an imaging protocol was proposed by Zahdi et al. [17]. Further investigations highlighted the pitfalls and best practices of tissue preparation methods for FT-IR spectroscopic analysis [18].

Gaydou et al took mid infrared imaging as a tool to investigate cell lines according to their infrared signature [19]. The cells were fixed in formalin and embedded into paraffin after centrifugation. Slices $8 \mu \mathrm{m}$ thick were cut and their infrared image acquired. From their samples, 2 spectral images were collected, one from the cell culture and another from the paraffinized one. For data pre-processing extended multiplicative signal correction (EMSC) was used to correct the spectra mathematically.

Mid-infrared imaging could be used to differentiate cell lines and could be a promising technique for in vivo image analysis of tumours in animal models. This would be a key step to achieve the final goal to make this dye-free technique applicable for intraoperative surgical procedures [20,21]. This means, that resection margins can be assessed by MIR characteristics.

The purpose of the present study was to prove that characteristic fingerprint regions are able to separate different cell lines representing normal and tumorous tissues by using label-free mid-infrared imaging.

\section{Materials and Methods}

\section{Aluminium Coated Slides}

Thin-film metal layers were deposited onto glass slides by vacuum evaporation to gain mid-infrared reflective surface. An electron-beam evaporation source was applied in a highvacuum chamber, in which the glass slides were fastened onto the rotary sample holder. Aluminium was evaporated at $10^{-4} \mathrm{~Pa}$ for $20 \mathrm{~min}$ at an accelerating voltage of $7 \mathrm{kV}$ and beam current of $200 \mathrm{~mA}$, resulting in a layer thickness of ca. $150 \mathrm{~nm}$.

\section{Cell Cultures}

A-375 melanoma (Suppl. Fig.1a) and HT-29 colorectal human cancer cells (Suppl. Fig.1b) were obtained from ATCC (Manassas, Virginia, USA). The CCD986SK fibroblasts (Suppl. Fig.1c) (human from ATCC) were selected as a nonneoplastic cell line for comparison. Cell media used were Dulbecco's modification of Eagle medium DMEM (Lonza Group Ltd., Basel, Switzerland) supplemented with $10 \%$ fetal bovine serum (FBS) (Euroclone Ltd., Pero, Italy) and cells were kept in a humidified incubator at $37{ }^{\circ} \mathrm{C}$ and $5 \% \mathrm{CO}_{2}$. For infrared imaging evaluation cells were trypsinized and cell suspension was dropped on UV sterilized aluminium coated slides. Slides were placed in Petri dishes and immersed in phosphate-buffered saline (PBS), Whatman paper was used to avoid evaporation and the cells were allowed to attach 
Fig. 1 Intensity of the scattering light while travelling through more cells. a: principle of transflectance $\mathbf{b}$ : transflectance of single cell layer c: overlapping cells resulting in weak signal (low mean T\%). Spectra of a and $\mathbf{c}$ were removed and final analyses were done on single cell layer $\mathbf{b}$ a

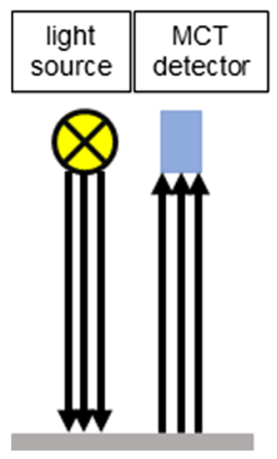

b

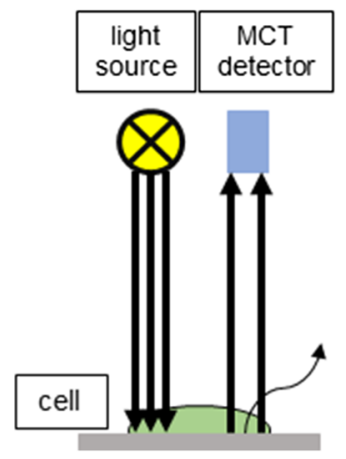

C

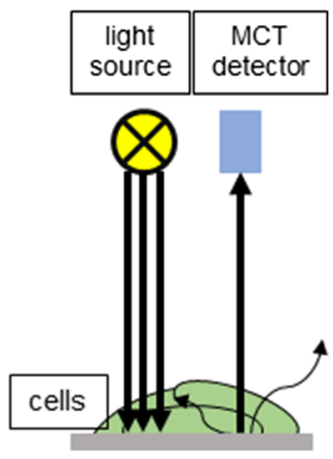

overnight in the incubator. On the following day, cells were fixed using ethanol (EtOH) then washed with PBS and allowed to dry.

\section{Infrared Imaging}

The wavelength range of NIR is defined from 780 to $2500 \mathrm{~nm}$ (12820-4000 $\mathrm{cm}^{-1}$ - since due to the dispersed Fouriertransform (FT) spectrophotometers the wavenumber is typically measured in units of $\mathrm{cm}^{-1}$ ), the wavelengths of MIR are between $2500 \mathrm{~nm}$ and $25,000 \mathrm{~nm}\left(4000-400 \mathrm{~cm}^{-1}\right)$ and the FIR range is between 25 and $1000 \mu \mathrm{m}\left(400-10 \mathrm{~cm}^{-1}\right)$. The higher the wavenumber, the higher the energy of the light. NIR and MIR photons elevate the chemical bonds to higher energy level, causing deformation motions (e.g. angular changes).

Fourier transform mid-infrared imaging was used for collecting spectra with transflection optical setup. Spotlight 400 microscope (Perkin Elmer Inc., Waltham, Massachusetts, USA) was connected to Spectrum 400 spectrophotometer used for scanning images. The Mercury Cadmium Tellurite (MCT) detector collected spectra with $4000-648 \mathrm{~cm}^{-1}$ wavelength range using step $4 \mathrm{~cm}^{-1}$, resolution $8 \mathrm{~cm}^{-1}$. The $300 \mu \mathrm{m} \times 550 \mu \mathrm{m}$ images were scanned by pixel size $6.25 \mu \mathrm{m} \times 6.25 \mu \mathrm{m}$ and 32 scans per pixel. A single image contained $48 \times 88$ pixels and resulted 4224 spectra. The same size areas were selected to image the three cell lines attached on three separate slides.

\section{Data Processing}

\section{Principal Component Analysis}

Principal component analysis is an unsupervised variablereduction technique. The different effects of the variables can be visualized through loadings and the scores represent the samples. A total of 12 PCA models were built to analyse our data. The obtained spectra can be collected into a table, where the rows can be referred to as samples and the columns as variables. In case of a whole range of measured IR spectra there are 838 wavenumbers $\left(4000-648 \mathrm{~cm}^{-1}\right)$ considered as variables. An infrared image contains a large amount of data: $\mathrm{x}$ and $\mathrm{y}$ set pixel location and each optical frequency band is described by a variable. This multidimensional dataset can be processed via data/dimension reduction to keep the variability. Every spectrum is represented by principal component scores and can be visualized by plots. Colouring the points makes human understanding easier. Unscrambler X 10.4 (CAMO Software AS, Oslo, Norway) software was applied to perform the PCAs and LDAs.

\section{Atmospheric Correction and Noise Reduction}

The presence of $\mathrm{H}_{2} \mathrm{O}$ and $\mathrm{CO}_{2}$ are mid-infrared absorbing molecules, hindering the identification of some analytes [22]. The acquired images were treated with two built-in algorithms of the SpectrumIMAGE R1.6.5.0396 software (Perkin Elmer Inc., Waltham, Massachusetts, USA) for atmospheric correction and noise reduction. The atmospheric $\mathrm{CO}_{2} /$ $\mathrm{H}_{2} \mathrm{O}$ suppression by the least square fitting of the algorithm effected the atmospheric correction of the spectra [23]. The noise reduction was based on a 20 -factor PCA. Since the noise has lower weights, the 20 -factor based reconstructed spectrum is noise reduced. This method does not lead to the broadening of the spectrum peaks, unlike smoothing.

\section{Linear Discriminant Analysis}

Linear Discriminant Analysis is a supervised classification method. $12 \mathrm{LDA}$ models were also created and run for further analysis of our data. LDA is the simplest of all possible classification methods that are based on Bayes' formula [24]. It is based on the normal distribution assumption as well as on the assumption that the covariance matrices of the two (or more) groups are identical. The linear method is used when the difference between two groups can be represented by a linear function. The confusion matrix is a matrix used for visualization of classification results from supervised methods such as linear discriminant analysis classification. It carries information about the predicted and actual classifications of samples, with each row showing the instances in a predicted class, and each column 
representing the instances in an actual class. The projected spectra can be visualised using two-dimensional spaces. The points lying close to zero for a class are associated with the class.

\section{Accuracy and Cohen's Kappa Method}

The performance of classification models are most often described by their confusion matrix - also known as error matrix. Sensitivity and specificity are interpretable with a $2 \times 2$ table (binary classifier). Our model has three classes of data, the three cell lines. Diagonal elements are correctly classified, the off-diagonal elements represent the number of misclassified spectra. To compare the performance of the models, Cohen's Kappa and accuracy are the two indicators. The higher the value the better the model performance. The overall accuracy answers the question how often the classifier is correct? Cohen's Kappa is a metric describing the relation between observed and expected accuracy. It presents the performance of the classification. Landis and Koch consider 00.20 as slight, $0.21-0.40$ as fair, $0.41-0.60$ as moderate, $0.61-$ 0.80 as substantial, and $0.81-1$ as almost perfect [25].

\section{Results}

Our novel method used cancer cell line MIR spectra, which were pre-processed with atmospheric correction and noise reduction and were divided into 6 groups according to their mean transmittance (T\%) value, calculated from the whole $4000-648 \mathrm{~cm}^{-1}$ range. These groups of spectra are observable in Suppl. Fig.2. First, the large amount of measured spectra had to be prefiltered to eliminate the spectra from cell free pixels showing too high mean $\mathrm{T} \%$, this was then followed by removing spectra from pixels containing too thick cell layers (i.e. overlapping cells) resulting in too low mean T\% (Fig. 1). Therefore, the finally analysed population represented a systematically reduced number of spectra.

In case of HT-29 carcinoma cells some regions were cellfree (Fig. 2a, the pink areas), some were absorbing too much light (Fig. 2a, the blue areas).

The final analysis of acquired images was filtered by the mean transmittance. In case of A375 melanoma cells, the first group comprised the $0-50 \%$ mean $\mathrm{T} \%$ range, which was followed by increasing $10 \%$ steps till $100 \%$ (Suppl. Fig.2). The spectra with lower than $50 \mathrm{~T} \%$ were not useful because the peaks were deformed (e.g. 'U' shape of $\mathrm{NH}$ bond instead of typical ' $V$ ' shape at $3500-3300 \mathrm{~cm}^{-1}$ range). These same groups of the cell images will be packed together for further analyses. The remaining 50-80\% range was divided into 6 pieces of 5 T\% narrow groups (i.e. $50-55 \%, \ldots, 75-80 \%$ ). For each group, PCAs and LDAs were performed on all combinations of the spectral range. The reflecting cell-free surface showed high transmittance $(>80 \%)$.
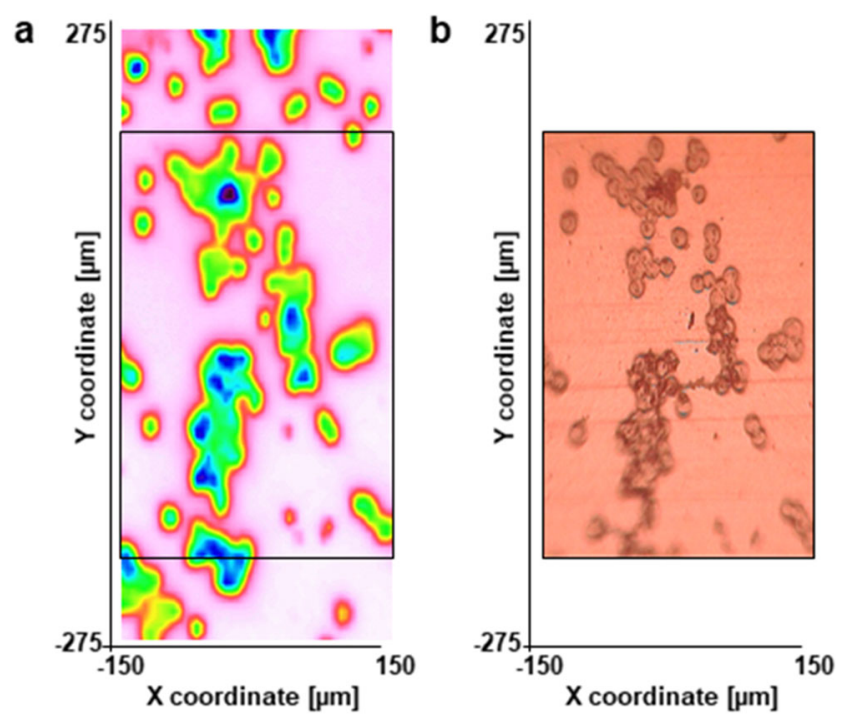

Fig. 2 Representative images of ethanol fixed HT-29 cells. a: The complete measured area showing cell-free areas in pink, cells in green and the thick high absorbing regions as blue b: visible light microscopy image of the marked area on panel a

Analysing the 5\% ranges of human cancer and normal cell spectra with PCA the 50-55 T\% range (out of 6 systematically tested 5\% ranges of spectra) resulted in the best separation (Suppl, Fig. 3). The 1800-648 $\mathrm{cm}^{-1}$ region performed better than the whole spectrum range. The fingerprint region (1800$648 \mathrm{~cm}^{-1}$ ) absorption bands represented the biological complexity of samples in a more pronounced manner and allowed better separation. The purpose of PCA discrimination in our method is the visual testing of the separation, to present qualitative results. The number of misclassifications must be interpreted with the actual classes. For this reason, LDA is the chosen supervised method to classify the cells. Figure 3a shows the confusion matrix of the whole region 65-70 T\% range results. Only 19 non-transformed cell representing data were misclassified. Figure $3 b-d$ display the spectra points on two-dimension plots. The tumour representing groups mingled with each other, these moderated the accuracy, which was $93.92 \%$. Fingerprint region analysis always resulted in higher accuracy then whole spectrum analysis. The supervised LDA models showed satisfying results on all mean transmittance datasets, both concerning accuracy and Cohen's Kappa values, which were high. The exact values are listed in Table 1 and visualized on Suppl. Fig. 4. The best separation was reached in the fingerprint region with 70-75 T\% range resulting $99.84 \%$ accuracy. All LDA model confusion matrices are shown in Suppl. Table 1.

\section{Discussion}

Complete resection of solid tumours is usually associated with the best quality of life and possible long term survival of 
a

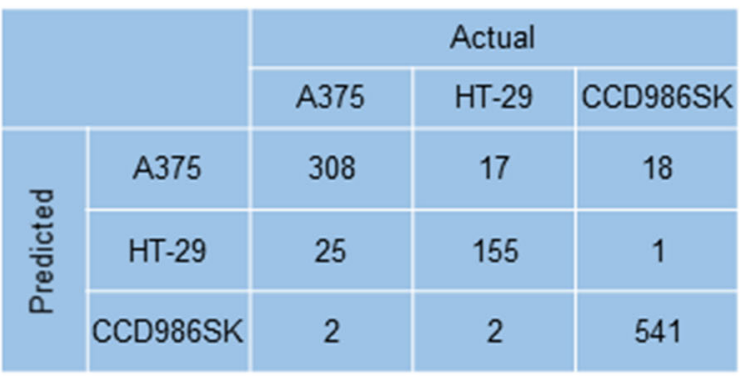

C

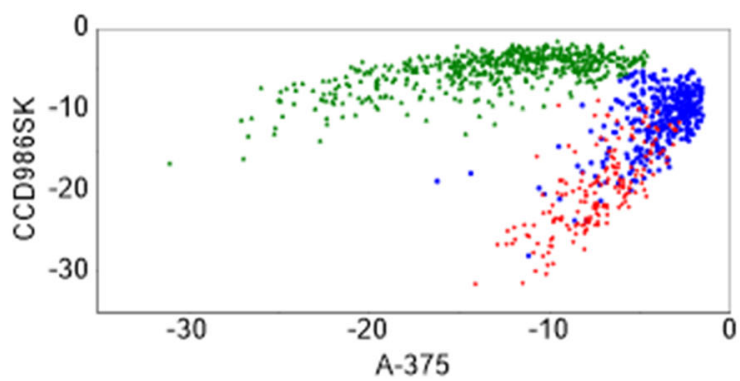

b
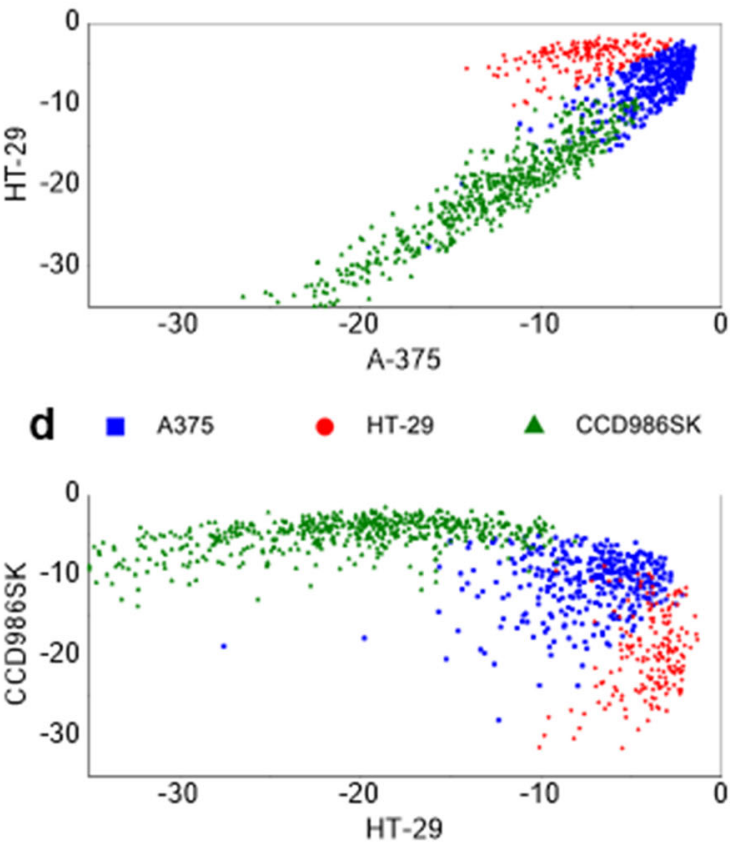

Fig. 3 a: Confusion matrix of the whole region 65-70 T\% LDA. b, $\mathbf{c}$ and $\mathbf{d}$ are the two dimension plots of projected scores coloured by the cell lines (A-375 - blue, HT-29 - red, CCD986SK - green)

tumour patients. Precise evaluation of the tumour extent and surgical resection margins requires not only intraoperative macroscopical observation but histological verifications as well. Routinely, this is achieved by frozen section technology. There is a constant need for intraoperative on site method to assess the resection margins, however, so far no reliable method gained acceptance in the daily practices of surgical routine. Jansen-Winkeln et al demonstated a promising dye-free hyperspectral imaging feasibility study involving 20 patients who underwent colorectal surgery to determine the resection margin [26].

In our study, label-free mid infrared imaging was used to acquire spectra from three human cell lines after ethanol fixation: two different cancer cell lines and one fibroblast cell line as control. The informative spectra with good signal-tonoise ratio were selected according to the mean $\mathrm{T} \%$ of the whole measured wavenumber region $\left(4000-648 \mathrm{~cm}^{-1}\right)$.
In the present study, we approached the problem from a general point of view that narrowed the whole image spectra into an informative subgroup. Mean T\% based selection is not common, since mostly manual selection is used. The advantage of the applied T\% selection is its objectivity and reproducibility. This basic mathematical approach allowed us to get rid of the aluminium background with small $\mathrm{T} \%$ as well as of the deformed spectra, owing to e.g. overlapping cells, therefore, we were finally able to select the appropriate spectra of cells. The spectrum with the fingerprint region might be specific for different normal tissues as well as for different pathological alterations including benign and malignant tumours. This depends on the characteristics of the fingerprint region and might identify the tissue type or lesion.

The data analysis of Gaydou et al is in contrast with our approach since we filtered the spectra instead of correcting them [19]. Due to filtering, the number of spectra was

Table 1 Accuracy and Cohen's Kappa values of the built LDA models

\begin{tabular}{|c|c|c|c|c|c|c|}
\hline & $50 \_55 \mathrm{~T} \%$ & $55 \_60 \mathrm{~T} \%$ & 60_65 T\% & $65 \_70 \mathrm{~T} \%$ & $70 \_75 \mathrm{~T} \%$ & 75_80 T\% \\
\hline \multicolumn{7}{|l|}{ LDA accuracy $(\%)$} \\
\hline Whole region $4000-650 \mathrm{~cm}^{-1}$ & 89,220 & 89,160 & 92,150 & 93,920 & 92,650 & 91,260 \\
\hline Fingerprint region $1800-650 \mathrm{~cm}^{-1}$ & 99,400 & 99,510 & 97,970 & 99,250 & 99,840 & 99,790 \\
\hline \multicolumn{7}{|l|}{ Cohen's kappa } \\
\hline Whole region $4000-650 \mathrm{~cm}^{-1}$ & 0,827 & 0,825 & 0,872 & 0,899 & 0,880 & 0,858 \\
\hline Fingerprint region $1800-650 \mathrm{~cm}^{-1}$ & 0,990 & 0,992 & 0,967 & 0,988 & 0,997 & 0,997 \\
\hline
\end{tabular}


reduced, however, the number of spectra remained unchanged during correction, while some wavelength values were modified by the EMSC algorithm. Quality input spectra for the analysis could be reached by either filtering or correction approaches. Our novel idea was to calculate the mean T\% value from each spectrum and test this value during the filtering.

The limitation of our model was the transflectance imaging set-up using aluminium coated glass slides. A possible diagnostic tool with a built in endoscope could be based on attenuated total reflection [27] or simple transmission by encompassing the tissue.

PCAs were performed on all the investigated subgroups on both the whole (i.e. $4000-648 \mathrm{~cm}^{-1}$ ) and fingerprint (1800-648 $\mathrm{cm}^{-1}$ ) regions. As a visual result the 50-55 mean T\% range, $1800-648 \mathrm{~cm}^{-1}$ spectra obtained from ethanol fixed cells presented the best grouping. We successfully demonstrated the feasibility of our infrared method to separate different human cell types by their filtered mid-infrared spectra with highlighted range. Non-linear supervised computation intensive models (e.g. artificial neural networks) have spread fast, however, it is not easy to interpret the results and effects of the variables. In addition, the risk of overfitting is much higher than by using PCA [28]. The first two factors described for the spectra points for the grouping were similar in the majority of our cases, with some overlaps observed in our cases too. In conclusion, our recommendation is to use the $1800-648 \mathrm{~cm}^{-1}$ MIR spectral range for diagnostic applications. Based on our results mean T\% based selection should be considered as a spectrum pretreatment before analysis.

LDA was chosen as supervised classification method, which performed satisfactorily on all investigated mean transmittance ranges. The fingerprint region accuracy and Cohen's kappa values were constantly higher than the whole region model results. These indicators of the LDA model have shown an excellent power of classification.

The tumour microenvironment and the normal cell-free matrix were not investigated, since only tumour cells and normal cells were compared to each other. As a next step, numerous different normal and transformed cell type spectra should be collected into a spectra library. The challenging issue is to identify and image the tumour-infiltrating immune cells in the stroma of the tumour [29].

Our novel approach showed that after using a generalized spectra filtering the proper supervised or unsupervised mathematical analysis enables the separation of normal and tumorous samples even in case of partially overlapping spectra. This novel, marker-free approach and the fiber development will facilitate the spread of new diagnostic in vivo applications of mid-infrared imaging tools. Our in vitro data suggests that this novel method can be further developed into an in vivo testing system which requires further investigations.
Acknowledgments This work was supported by the Higher Education Excellence Program of the Ministry of Human Capacities in the frame of Biotechnology research area of Budapest University of Technology and Economics (BME FIKP-BIO) and grant EFOP-3.6.3-VEKOP-162017-00009.

Funding Information Open access funding provided by Semmelweis University (SE).

\section{Compliance with Ethical Standards}

Conflict of Interest The authors declare that they have no conflicts of interest.

Open Access This article is licensed under a Creative Commons Attribution 4.0 International License, which permits use, sharing, adaptation, distribution and reproduction in any medium or format, as long as you give appropriate credit to the original author(s) and the source, provide a link to the Creative Commons licence, and indicate if changes were made. The images or other third party material in this article are included in the article's Creative Commons licence, unless indicated otherwise in a credit line to the material. If material is not included in the article's Creative Commons licence and your intended use is not permitted by statutory regulation or exceeds the permitted use, you will need to obtain permission directly from the copyright holder. To view a copy of this licence, visit http://creativecommons.org/licenses/by/4.0/.

\section{References}

1. Dolgin E (2018) Bringing down the cost of cancer treatment. Nature 555(7695):S26-S29. https://doi.org/10.1038/d41586-01802483-3

2. Prades J, Remue E, van Hoof E, Borras JM (2015) Is it worth reorganising cancer services on the basis of multidisciplinary teams (MDTs)? A systematic review of the objectives and organisation of MDTs and their impact on patient outcomes. Health Policy 119(4): 464-474. https://doi.org/10.1016/j.healthpol.2014.09.006

3. Orosco RK, Tapia VJ, Califano JA, Clary B, Cohen EEW, Kane C, Lippman SM, Messer K, Molinolo A, Murphy JD, Pang J, Sacco A, Tringale KR, Wallace A, Nguyen QT (2018) Positive surgical margins in the 10 Most common solid cancers. Sci rep-Uk 8. Doi: ARTN 5686 10.1038/s41598-018-23403-5

4. Jones EA, Simon D, Karancsi T, Balog J, Pringle SD, Takats Z (2019) Matrix assisted rapid evaporative ionization mass spectrometry. Anal Chem 91(15):9784-9791. https://doi.org/10.1021/acs. analchem.9b01441

5. Bunaciu AA, Hoang VD, Aboul-Enein HY (2017) Vibrational micro-spectroscopy of human tissues analysis: review. Crit Rev Anal Chem 47(3):194-203. https://doi.org/10.1080/10408347. 2016.1253454

6. Haque A, Faizi MS, Rather JA, Khan MS (2017) Next generation NIR fluorophores for tumor imaging and fluorescence-guided surgery: a review. Bioorg Med Chem 25(7):2017-2034. https://doi. org/10.1016/j.bmc.2017.02.061

7. Wolthuis R, Travo A, Nicolet C, Neuville A, Gaub MP, Guenot D, Ly E, Manfait M, Jeannesson P, Piott O (2008) IR spectral imaging for histopathological characterization of Xenografted human colon carcinomas. Anal Chem 80(22):8461-8469. https://doi.org/10. 1021/ac801191x

8. Silva JSF, Silva JYR, de Sa GF, Araujo SS, Filho MAG, Ronconi CM, Santos TC, Junior SA (2018) Multifunctional system polyaniline-decorated ZIF-8 nanoparticles as a new chemo- 
Photothermal platform for cancer therapy. ACS Omega 3(9): 12147-12157. https://doi.org/10.1021/acsomega.8b01067

9. Oh Y, Quan YH, Choi Y, Kim CK, Kim H, Kim HK, Kim BM (2013) Intraoperative combined color and fluorescent images-based sentinel node mapping in the porcine lung: comparison of indocyanine green with or without albumin premixing. J Thorac Cardiov Sur 146(6):1509-1515. https://doi.org/10.1016/j.jtcvs.2013.02.044

10. Ishizawa T, Fukushima N, Shibahara J, Masuda K, Tamura S, Aoki T, Hasegawa K, Beck Y, Fukayama M, Kokudo N (2009) Realtime identification of liver cancers by using Indocyanine green fluorescent imaging. Cancer 115(11):2491-2504. https://doi.org/ 10.1002/cncr.24291

11. Balan V, Mihai CT, Cojocaru FD, Uritu CM, Dodi G, Botezat D, Gardikiotis I (2019) Vibrational spectroscopy fingerprinting in medicine: from molecular to clinical practice. Materials 12 (18). Doi: ARTN 2884 10.3390/ma12182884.

12. Bogomolov A, Belikova V, Zabarylo UJ, Bibikova O, Usenov I, Sakharova T, Krause H, Minet O, Feliksberger E, Artyushenko V (2017) Synergy effect of combining fluorescence and mid infrared fiber spectroscopy for kidney tumor diagnostics. Sensors (Basel) 17(11). https://doi.org/10.3390/s17112548

13. Sojka L, Tang Z, Furniss D, Sakr H, Fang Y, Beres-Pawlik E, Benson TM, Seddon AB, Sujecki S (2017) Mid-infrared emission in Tb3+-doped selenide glass fiber. J Opt Soc Am B 34(3):A70 A79. https://doi.org/10.1364/Josab.34.000a70

14. Nallala J, Lloyd GR, Hermes M, Shepherd N, Stone N (2017) Enhanced spectral histology in the colon using high-magnification benchtop FTIR imaging. Vib Spectrosc 91:83-91. https://doi.org/ 10.1016/j.vibspec.2016.08.013

15. Joro R, Laaperi AL, Dastidar P, Soimakallio S, Kuukasjarvi T, Toivonen T, Saaristo R, Jarvenpaa R (2008) Imaging of breast cancer with mid- and long-wave infrared camera. J Med Eng Technol 32(3):189-197. https://doi.org/10.1080/ 03091900701234358

16. Paraskevaidi M, Morais CLM, Lima KMG, Ashton KM, Stringfellow HF, Martin-Hirsch PL, Martin FL (2018) Potential of mid-infrared spectroscopy as a non-invasive diagnostic test in urine for endometrial or ovarian cancer. Analyst 143(13):31563163. https://doi.org/10.1039/c8an00027a

17. Zohdi V, Whelan DR, Wood BR, Pearson JT, Bambery KR, Black MJ (2015) Importance of tissue preparation methods in FTIR micro-spectroscopical analysis of biological tissues: 'traps for new users'. PLoS One 10(2):e0116491. https://doi.org/10.1371/journal. pone. 0116491

18. Sreedhar H, Varma VK, Nguyen PL, Davidson B, Akkina S, Guzman G, Setty S, Kajdacsy-Balla A, Walsh MJ (2015) Highdefinition Fourier transform infrared (FT-IR) spectroscopic imaging of human tissue sections towards improving pathology. J Vis Exp 95:52332. https://doi.org/10.3791/52332

19. Gaydou V, Polette M, Gobinet C, Kileztky C, Angiboust JF, Manfait M, Birernbaut P, Piot O (2016) Vibrational analysis of lung tumor cell lines: implementation of an invasiveness scale based on the cell infrared signatures. Anal Chem 88(17):8459-8467. https:// doi.org/10.1021/acs.analchem.6b00590

20. Grosserueschkamp F, Kallenbach-Thieltges A, Behrens T, Bruning T, Altmayer M, Stamatis G, Theegarten D, Gerwert K (2015) Marker-free automated histopathological annotation of lung tumour subtypes by FTIR imaging. Analyst 140(7):2114-2120. https://doi. org/10.1039/c4an01978d

21. Petersen D, Mavarani L, Niedieker D, Freier E, Tannapfel A, Kotting C, Gerwert K, El-Mashtoly SF (2017) Virtual staining of colon cancer tissue by label-free Raman micro-spectroscopy. Analyst 142(8):1207-1215. https://doi.org/10.1039/c6an02072k

22. Perez-Guaita D, Kuligowski J, Quintas G, Garrigues S, de la Guardia M (2013) Atmospheric compensation in Fourier transform infrared (FT-IR) spectra of clinical samples. Appl Spectrosc 67(11): 1339-1342. https://doi.org/10.1366/13-07159

23. Hoult RA (2003) Angle of rotation sensor having a rotating annular magnet and two ferritic stator halves United States Patent

24. Hastie T, Tibshirani R, Friedman JH (2009) The elements of statistical learning : data mining, inference, and prediction. Springer series in statistics, 2nd edn. Springer, New York, NY

25. Landis JR, Koch GG (1977) The measurement of observer agreement for categorical data. Biometrics 33(1):159-174

26. Jansen-Winkeln B, Holfert N, Kohler H, Moulla Y, Takoh JP, Rabe SM, Mehdorn M, Barberio M, Chalopin C, Neumuth T, Gockel I (2019) Determination of the transection margin during colorectal resection with hyperspectral imaging (HSI). Int J Color Dis 34(4): 731-739. https://doi.org/10.1007/s00384-019-03250-0

27. Chan KLA, Kazarian SG (2016) Attenuated total reflection Fouriertransform infrared (ATR-FTIR) imaging of tissues and live cells. Chem Soc Rev 45(7):1850-1864. https://doi.org/10.1039/ c5cs00515a

28. Smialowski P, Frishman D, Kramer S (2010) Pitfalls of supervised feature selection. Bioinformatics 26(3):440-443. https://doi.org/10. 1093/bioinformatics/btp621

29. Hendry S, Salgado R, Gevaert T, Russell PA, John T, Thapa B, Christie M, van de Vijver K, Estrada MV, Gonzalez-Ericsson PI, Sanders M, Solomon B, Solinas C, Van den Eynden G, Allory Y, Preusser M, Hainfellner J, Pruneri G, Vingiani A, Demaria S, Symmans F, Nuciforo P, Comerma L, Thompson EA, Lakhani S, Kim SR, Schnitt S, Colpaert C, Sotiriou C, Scherer SJ, Ignatiadis M, Badve S, Pierce RH, Viale G, Sirtaine N, Penault-Llorca F, Sugie T, Fineberg S, Paik S, Srinivasan A, Richardson A, Wang Y, Chmielik E, Brock J, Johnson DB, Balko J, Wienert S, Bossuyt V, Michiels S, Ternes N, Burchardi N, Luen SJ, Savas P, Klauschen F, Watson PH, Nelson BH, Criscitiello C, O'Toole S, Larsimont D, de Wind R, Curigliano G, Andre F, Lacroix-Triki M, van de Vijver M, Rojo F, Floris G, Bedri S, Sparano J, Rimm D, Nielsen T, Kos Z, Hewitt S, Singh B, Farshid G, Loibl S, Allison KH, Tung N, Adams S, Willard-Gallo K, Horlings HM, Gandhi L, Moreira A, Hirsch F, Dieci MV, Urbanowicz M, Brcic I, Korski K, Gaire F, Koeppen H, Lo A, Giltnane J, Rebelatto MC, Steele KE, Zha J, Emancipator K, Juco JW, Denkert C, Reis-Filho J, Loi S, Fox SB (2017) Assessing tumor-infiltrating lymphocytes in solid tumors: a practical review for pathologists and proposal for a standardized method from the international Immunooncology biomarkers working group: part 1: assessing the host immune response, TILs in invasive breast carcinoma and ductal carcinoma in situ, metastatic tumor deposits and areas for further research. Adv Anat Pathol 24(5):235-251. https://doi.org/10.1097/PAP.0000000000000162

Publisher's Note Springer Nature remains neutral with regard to jurisdictional claims in published maps and institutional affiliations. 